\title{
Acceptability of female-controlled HIV/STI prevention options among professionals in Dhaka, Bangladesh
}

\author{
Zaman Ara ${ }^{\prime}$, Nilufar Begum², Chidi V. Nweneka ${ }^{3}$
}

${ }^{1}$ Senior Programme Officer, Reproductive Health, UNFPA, Bangladesh Country Office, Dhaka, Bangladesh; ${ }^{2}$ Medical Consultant, Ashar Alo, Bangladesh, Dhaka, Bangladesh; ${ }^{3}$ Technical Adviser, Pro-Hope International, Banjul, The Gambia.

\begin{abstract}
Millions of women worldwide lack the power to protect themselves from HIV; current prevention options require cooperation from the male partners. Limited prospects for an HIV vaccine and continued escalation of HIV make female-controlled HIV/STI prevention options like microbicides desirable. While socio-cultural factors could reduce acceptability of these options by vulnerable women, opinion leaders like health personnel and teachers could positively influence their acceptability. The aim of this study was to assess the acceptability of female-controlled HIV/STI prevention options among medical doctors, nurses, pharmacists and secondary school teachers in Dhaka, Bangladesh. A cross-sectional study was conducted using a selfadministered semi-structured questionnaire among 375 professionals (nurses, doctors, pharmacists and teachers). The questionnaire assessed the respondents' perception of HIV, and their attitudes towards female-controlled HIV/STI prevention options such as female condoms and vaginal microbicides. The study revealed that $98.4 \%$ of the respondents were of the opinion that women should determine their HIV/STI prevention options, while $89.3 \%$ agreed that options which empower women would be acceptable. It was also found that $18.4 \%$ would use the female condoms while $34.4 \%$ would use vaginal microbicides. Factors associated with willingness to use the female-controlled prevention options were HIV risk perception, marital status, profession, and duration in profession. There was no association between willingness to use female condoms and willingness to use the vaginal microbicides. While male condom use was positively associated with willingness to use female condom, there was no significant relationship between male condom use and willingness to use the vaginal microbicides. The study showed that professionals strongly supported HIV/STI prevention options that are female-controlled, with most preferring vaginal microbicides to the female condoms. Such support would inform the design of appropriate interventions to prepare the professionals for the eventual advent of an effective microbicide as a HIV/AIDS prevention option.
\end{abstract}

Keywords: HIV/STI, Acceptability, Professionals, Female-controlled, Contraceptives.

\section{Introduction}

Millions of women worldwide lack the power to protect themselves from HIV and other sexually transmitted infections (STIs). ${ }^{1,2}$ Consequently, current HIV/AIDS prevention options (such as abstinence, mutual faithfulness of sexual partners, and the use of barrier methods such as the male condom, which are potentially useful in protecting against the STIs, including HIV) are inadequate to protect women against HIV/AIDS for the simple reason that they depend on the co-operation of the male partner. Furthermore, in most parts of the world, especially in resource poor settings, various cultural, religious, social and economic factors can discourage the use of these preventive methods. ${ }^{2,3}$ The reduced effectiveness of these options to protect women against HIV/AIDS has been attributed to the limited control of women in many settings over their sexuality, coupled with widespread partner violence and such practices as wife inheritance and polygamy, which makes sexual negotiation difficult. ${ }^{4-6}$

A review of the trend of HIV infection globally has shown that women have persistently remained disproportionately infected

\section{Practice points}

- Millions of women worldwide lack the power to protect themselves from HIV and other STIs.

- Limited prospects for an HIV vaccine and continued escalation of HIV make female-controlled HIV/STI prevention options desirable.

- This study suggests that professionals (nurses, doctors, pharmacists and teachers) would support female-controlled prevention options particularly the vaginal microbicides.

- Factors associated with willingness to use the femalecontrolled options were HIV risk perception, marital status, profession, and duration in profession.

- Such support would inform the design of appropriate interventions to prepare these professionals for the eventual advent of an effective microbicide as a HIV/AIDS prevention option.

Correspondence: Dr. Zaman Ara, Senior Programme Officer, Reproductive Health, UNFPA, Bangladesh Country Office, IDB Bhaban (15th Floor), Sher-E-Bangla Nagar, Dhaka, Bangladesh. E-mail: dhakazaman@yahoo.com. 
by HIV. ${ }^{1,7}$ In many parts of the world, more than half of all the new HIV infections occur among women, and most of these infections occur through sexual routes. ${ }^{1-7}$ To control this situation, and considering the various social, cultural and religious barriers already described above, an HIV/AIDS prevention option which is largely controlled by women is desirable. With limited prospects of HIV vaccine and continued escalation of HIV, microbicides and female condoms have been proposed as potentially viable option for protecting vulnerable women. ${ }^{8,9}$ One of the suggested benefits of the female-controlled HIV/STI prevention options include the fact that being under the control of women, these prevention options might be used discretely without the partner's knowledge. For example, a study in Zimbabwe reported that about $13 \%$ of women surveyed used the female condoms without their partners' knowledge. ${ }^{10}$ Similar experience has been suggested as being even more possible with the vaginal microbicide. ${ }^{11} \mathrm{~A}$ number of reports from both developing and developed countries have suggested that the vaginal microbicide will be an acceptable HIV/STI prevention option..$^{3,9-15}$

While the use of the female condom has not been encouraging, ${ }^{16,17}$ reports indicate that with appropriate motivation, female condom acceptability is likely to increase. ${ }^{16,17}$ On the other hand, no vaginal microbicide has yet been approved for use in HIV/AIDS prevention; however, the results of the Caprisa 004 study in South Africa has given hope that a microbicide may become available soon. In addition, several reports have suggested that people from diverse socio-economic backgrounds would be willing to use the vaginal microbicide. ${ }^{9,10,12,13}$ It is likely that the subordinate roles that women play in most societies could potentially be a barrier to their use of an effective microbicide even if they desire to do so. And one issue that has been in the front burner since the early days of microbicides advocacy is the feasibility of finding a large enough market for the product when one is eventually developed. ${ }^{18-20}$ There have been suggestions that key opinion leaders such as health care professionals could significantly influence the acceptability and actual use of the vaginal microbicides. ${ }^{12,21}$ However, there is paucity of information on the attitudes of these professionals towards these products. Although there have been studies relating to the influence of family planning providers on the use of female condoms in many developing countries, ${ }^{16,17}$ non-family planning providers are also involved in the management and care of patients with STIs and HIV. Therefore understanding the attitudes of other health care professionals to the female-controlled HIV/STI prevention options will inform the design of appropriate interventions to promote the use of these products. Furthermore, since the female condom is also a female-controlled HIV/STI prevention option, it is likely that factors which affect its use might also affect the use of the vaginal microbicide.

Bangladesh has a population of 150 million and covers an area of about 147,570 square kilometers. Although the prevalence of HIV in Bangladesh is still very low, the country remains vulnerable to HIV because of proximity to high HIV prevalence countries with similar behavioral risk characteristics. For example, like in many other Asian countries, partner violence and unprotected commercial sex are common in Bangladesh. ${ }^{7}$ In the fourth round of national serological surveillance the HIV prevalence among injection drug users was $4 \%$, but remains less than $1 \%$ among other vulnerable groups such as commercial sex workers and men who have sex with men. The government of Bangladesh is currently implementing a wide range of actions against HIV/AIDS. It is likely that the vaginal microbicides will become one of the prevention options as soon as one becomes available. In that circumstance, the professional might be expected to play key roles in the social marketing of these products. To the best of our knowledge, we are not aware of any reports on the attitudes of Bangladeshi professionals to the vaginal microbicide. This study was conducted to explore the attitudes towards the femalecontrolled HIV/STI prevention options with particular reference to the female condom and vaginal microbicide and their acceptability among Bangladeshi professionals.

\section{Materials and Methods}

This was a cross-sectional descriptive study conducted among professionals in Dhaka, the capital city of Bangladesh. The participants included medical doctors, pharmacists, nurses and secondary school teachers. Each professional was required to complete a self administered semi-structured questionnaire. In addition to their demographic details, questions were asked about their HIV risk perception, male and female condom use experiences, and their attitudes towards female-controlled HIV/STI prevention options with particular reference to the vaginal microbicide. The data generated was analyzed using descriptive statistics. Various responses were first analyzed using proportions and percentages. Associations between variables were assessed using student $t$-test for continuous variables, and chi-squared test for categorical variables. Multivariable logistic regression analysis was used to control for confounders and to identify independent predictors of risk perception, willingness to use female condom and willingness to use vaginal microbicide. A $p$-value below 0.05 was considered as statistically significant. STATA version 8 (Stata Corporation, College Station, TX, USA) was used in the analysis.

\section{Results}

\section{Demographic characteristics}

Three hundred and seventy five professionals participated in the study comprising 184 males (49.1\%) and 191 females (50.9\%). The age range was $18-54$ years (mean 35.4 years, SD 6.9 years). The males were significantly younger than the females (mean age 34.4 years vs. 36.4 years, $p=0.005$ ). Eighty-eight $(23.5 \%)$ of the respondents were single, 265 (70.7\%) were married, while $22(5.9 \%)$ were widowed, separated or divorced. Significantly more females than males were in a marriage relationship $(\mathrm{P}<0.001)$. 
Information on sexual orientation was available for 351 respondents out of which $341(97.1 \%)$ were heterosexuals while $10(2.9 \%)$ were bisexuals. All the bisexuals were married people. Although more males were in a bisexual relationship (7 vs. 3), this was not statistically significant probably due to the small numbers of respondents. Of all the respondents, $122(32.5 \%)$ were medical doctors, 114 $(30.4 \%)$ were nurses, $70(18.7 \%)$ were pharmacists while 69 $(18.4 \%)$ were teachers. Approximately $70-90 \%$ of the doctors, nurses and teachers were married while only $40 \%$ of the pharmacists were married. The relationship between profession, marital status, number of years of professional practice and sexual partners are shown in Table 1 and Table 2.

Acceptability offemale-controlled HIV/STI prevention options Three hundred and sixty-nine (98.4\%) respondents agreed that women should be allowed to determine their HIV/STI prevention options. Of the six that felt that women should not be allowed to determine their HIV/STI prevention option, one person felt that this would cause women to begin to disrespect men and two respondents felt that the culture forbids a woman from taking such actions. The other three did not give any reason. When the respondents were asked if an HIV/STI prevention option which empowers the woman such as the female condoms and vaginal microbicides would be acceptable, 335 (89.3\%) agreed, 9 (2.4\%) disagreed while 31 (8.3\%) were undecided. Females were more likely to support this option than men (94.2\% [180/191] vs. $84.2 \%[155 / 184], p=0.004)$.

Table 1: Association between profession, marital status and sexual partners in the last 12 months

\begin{tabular}{|c|c|c|c|c|c|}
\hline \multirow{4}{*}{$\begin{array}{c}\text { Marital } \\
\text { Status }\end{array}$} & Profession & $\mathbf{N}$ & \multicolumn{3}{|c|}{ Number of sexual Partners } \\
\cline { 3 - 6 } & & & 0 & 1 & $\geq 2$ \\
\hline \hline \multirow{4}{*}{ Single } & Doctors & 32 & $28(87.5 \%)$ & $4(12.5 \%)$ & 40 \\
\cline { 2 - 6 } & Pharmacists & 39 & $20(51.3 \%)$ & $10(25.6 \%)$ & $9(23.1 \%)$ \\
\cline { 2 - 6 } & Nurses & 10 & $7(70.0 \%)$ & $3(30 \%)$ & 0 \\
\cline { 2 - 6 } & Teachers & 7 & $7(100 \%)$ & 0 & 0 \\
\hline \multirow{4}{*}{ Married } & Doctors & 86 & $1(1.2 \%)$ & $84(97.7 \%)$ & $1(1.2 \%)$ \\
\cline { 2 - 6 } & Pharmacists & 28 & 0 & $23(82.1 \%)$ & $5(17.9 \%)$ \\
\cline { 2 - 6 } & Nurses & 94 & $1(1.1 \%)$ & $93(98.9 \%)$ & 0 \\
\cline { 2 - 6 } & Teachers & 57 & 0 & $57(100 \%)$ & 0 \\
\hline \multirow{4}{*}{ Others } & Doctors & 4 & $3(75 \%)$ & $1(25 \%)$ & 0 \\
\cline { 2 - 6 } & Pharmacists & 3 & 0 & $1(33.3 \%)$ & $2(66.7 \%)$ \\
\cline { 2 - 6 } & Nurses & 10 & $10(100 \%)$ & 0 & 0 \\
\cline { 2 - 6 } & Teachers & $18(81.8 \%)$ & $2(9.1 \%)$ & $2(9.1 \%)$ \\
\hline
\end{tabular}

Table 2: Professional groups, number of years of professional practice and number of sexual partners in the last 12 months

\begin{tabular}{|c|c|c|c|c|c|c|}
\hline \multirow[t]{2}{*}{ Profession } & \multirow{2}{*}{$\begin{array}{l}\text { No of years in } \\
\text { Profession }\end{array}$} & \multirow{2}{*}{$\mathbf{N}$} & \multicolumn{3}{|c|}{ No of sexual Partner } & \multirow[t]{2}{*}{$p$ value } \\
\hline & & & 0 & 1 & 2 & \\
\hline \multirow{4}{*}{ Medical Doctor } & Less than 2 years & 21 & $13(61.9 \%)$ & $8(38.1 \%)$ & 0 & \multirow{4}{*}{$<0.001^{*}$} \\
\hline & 2 to 5 years & 24 & $13(54.2 \%)$ & $11(45.8 \%)$ & 0 & \\
\hline & 6 to 10 years & 31 & $5(16.1 \%)$ & $26(83.9 \%)$ & 0 & \\
\hline & Above 10 years & 46 & $1(2.2 \%)$ & $44(95.7 \%)$ & $1(2.2 \%)$ & \\
\hline \multirow{4}{*}{ Pharmacist } & Less than 2 years & 17 & $4(23.5 \%)$ & $9(52.9 \%)$ & $4(23.5 \%)$ & \multirow{4}{*}{0.32} \\
\hline & 2 to 5 years & 33 & $10(30.3 \%)$ & $14(42.4 \%)$ & $9(27.3 \%)$ & \\
\hline & 6 to 10 years & 15 & $6(40 \%)$ & $6(40 \%)$ & $3(20 \%)$ & \\
\hline & Above 10 years & 5 & 0 & $5(100 \%)$ & 0 & \\
\hline \multirow{4}{*}{ Nursing } & Less than 2 years & 8 & $5(62.5 \%)$ & $3(37.5 \%)$ & 0 & \multirow{4}{*}{$0.002 *$} \\
\hline & 2 to 5 years & 28 & $4(14.3 \%)$ & $24(85.7 \%)$ & 0 & \\
\hline & 6 to 10 years & 48 & $4(8.3 \%)$ & $44(91.7 \%)$ & 0 & \\
\hline & Above 10 years & 30 & $5(16.7 \%)$ & $25(83.3 \%)$ & 0 & \\
\hline \multirow{4}{*}{ Teaching } & Less than 2 years & 8 & $5(62.5 \%)$ & $3(37.5 \%)$ & 0 & \multirow{4}{*}{$0.002 *$} \\
\hline & 2 to 5 years & 10 & $1(10 \%)$ & $9(90 \%)$ & 0 & \\
\hline & 6 to 10 years & 37 & $6(16.2 \%)$ & $31(83.8 \%)$ & 0 & \\
\hline & Above 10 years & 14 & 0 & $14(100)$ & 0 & \\
\hline
\end{tabular}

*Values are significant $p<0.05$. 
Of the 40 who did not agree that women should be allowed to determine their HIV/STI prevention options, $12(30 \%)$ cited cultural disapproval as a reason, $8(20 \%)$ felt it was against social norms, $7(17.5 \%)$ cited religious disapproval while $13(32.5 \%)$ did not give any reason. Only $161(42.9 \%)$ of the respondents would be willing to support their spouses' decision to use female condoms or vaginal microbicides. More males than females would be wiling to support their spouses' decision to use female condoms and vaginal microbicides (112 [60.9\%] vs 49 [25.7\%], $p<0.001)$. The commonest reason for not supporting spouse' decision to use female condoms or vaginal microbicides was fear of possible adverse effects (34 [15.9\%]) (Table 3).

Table 3: Reasons for unwillingness to support spouse's decision to use either female condom or vaginal Microbicide

\begin{tabular}{|l|c|}
\hline Reasons for unwillingness $(\mathbf{n}=\mathbf{2 1 4})$ & Respondents \\
\hline My preference should over-ride his/her & $2(0.9 \%)$ \\
\hline My religion forbids it & $3(1.4 \%)$ \\
\hline My culture forbids it & $4(1.9 \%)$ \\
\hline My friends and associates will mock me & $1(0.5 \%)$ \\
\hline Fear of possible adverse effects & $34(15.9 \%)$ \\
\hline $\begin{array}{l}\text { Fear of possible effects on my sexual } \\
\text { experience }\end{array}$ & $9(4.2 \%)$ \\
\hline No reason & $149(69.6 \%)$ \\
\hline Others & $12(5.6 \%)$ \\
\hline
\end{tabular}

Female condom use

Of all the respondents, $262(70 \%)$ have heard of the female condom, $42(11.2 \%)$ have seen a female condom, but only 2 $(0.5 \%)$ have ever used the female condom. Approximately (74\%) of the pharmacists, $24 \%$ of the doctors, $19 \%$ of the teachers and $17 \%$ of the nurses have never heard of the female condom before. Majority of those who have heard of the female condom were married $\left(\chi^{2}=49.99\right.$ (2df), $p<0.001)$.

Only $69(18.4 \%)$ respondents showed their willingness to use the female condoms. About $41 \%$ of the pharmacists, $23.8 \%$ of the doctors and $8.8 \%(10 / 114)$ of the nurses expressed their willingness to use the female condoms (Figure 1). Among those who have heard of the female condom, only $38(14.5 \%)$ will be willing to use it; 113 (43.1\%) will not, while 111 (42.4) are undecided. About $45.2 \%$ of those who have seen the female condom will not be willing to use it. In a multivariable logistic regression analysis with willingness to use the female condom as the dependent variable, the factors that were significantly associated with willingness to use female condom were being single, current use of male condom, being a pharmacist or a doctor, older professionals (more than 6 years in the profession), and perception of being at risk of HIV.

On the reasons for not wanting to use the female condom, $68.3 \%$ cited no need for the female condom, $22 \%$ gave no reasons, while the rest gave other reasons which included cultural and religious factors. Nearly all those who either did not give any reasons for being unwilling to use the female condoms, or felt they had no need for it were either in a monogamous sexual relationship, or abstained from sex in the preceding 12 months.

\section{Vaginal microbicides}

One hundred and forty nine (39.7\%) of the respondents have heard of the vaginal microbicides. There were more doctors $(72.1 \%)$ and pharmacists $(64.3 \%)$ who have heard of the vaginal microbicide than nurses $(9.7 \%)$ and teachers $(7.3 \%)$ $(p<0.001)$. Three hundred and eighteen $(84.8 \%)$ of the respondents would be willing to support the use of vaginal microbicides. This strong support cuts across all the professions with the doctors offering the least support $(76.2 \%)$ (Figure 1). There was no association between willingness to use the female condom and willingness to support the use of the vaginal microbicide $(p=0.07)$. When the respondents were asked if they would be willing to use the vaginal microbicide if they knew it was effective in preventing HIV/STI, only $129(34.4 \%)$ answered that they would be willing to use it, while the rest were either unsure or would not use it. Only $127(40 \%)$ of those who would support the use of the vaginal microbicides would be willing to use one even if they knew it was effective in preventing HIV/STI. All those who will not use vaginal microbicide were either in a monogamous relationship or abstained from sex in the preceding 12 months.

\section{Male condom use and willingness to use female-controlled HIV/STI prevention options}

Two hundred and eighty-eight $(76.8 \%)$ of the respondents have used the male condoms, of which 152 (52.8\%) were still using the male condoms at the time of the study. After controlling for age, marital status, profession, gender, HIV risk perception, number of sexual partners, and duration in profession in a multivariable logistic regression, both previous use of male condom and current use of the male condom were strongly associated with willingness to use the female condom. Respondents who have ever used the male condoms were 2.7 times more likely to be willing to use the female condoms than those who had never used the male condoms (95\% CI: 1.16 to 6.29$)$, while those who currently use the male condoms are about twice as likely to be willing to use the female condoms than those who do not currently use the male condoms ( $95 \% \mathrm{CI}$ : 1.16 to 3.13 ). However, after controlling for the above confounders, there was no association between previous or present use of the male condom and willingness to use or support the use of the vaginal microbicide (Table 4). Table 5 summarizes other factors associated with willingness to use female condoms and vaginal microbicides. 
Figure 1: Willingness of professionals to use female-controlled HIV/STI prevention options

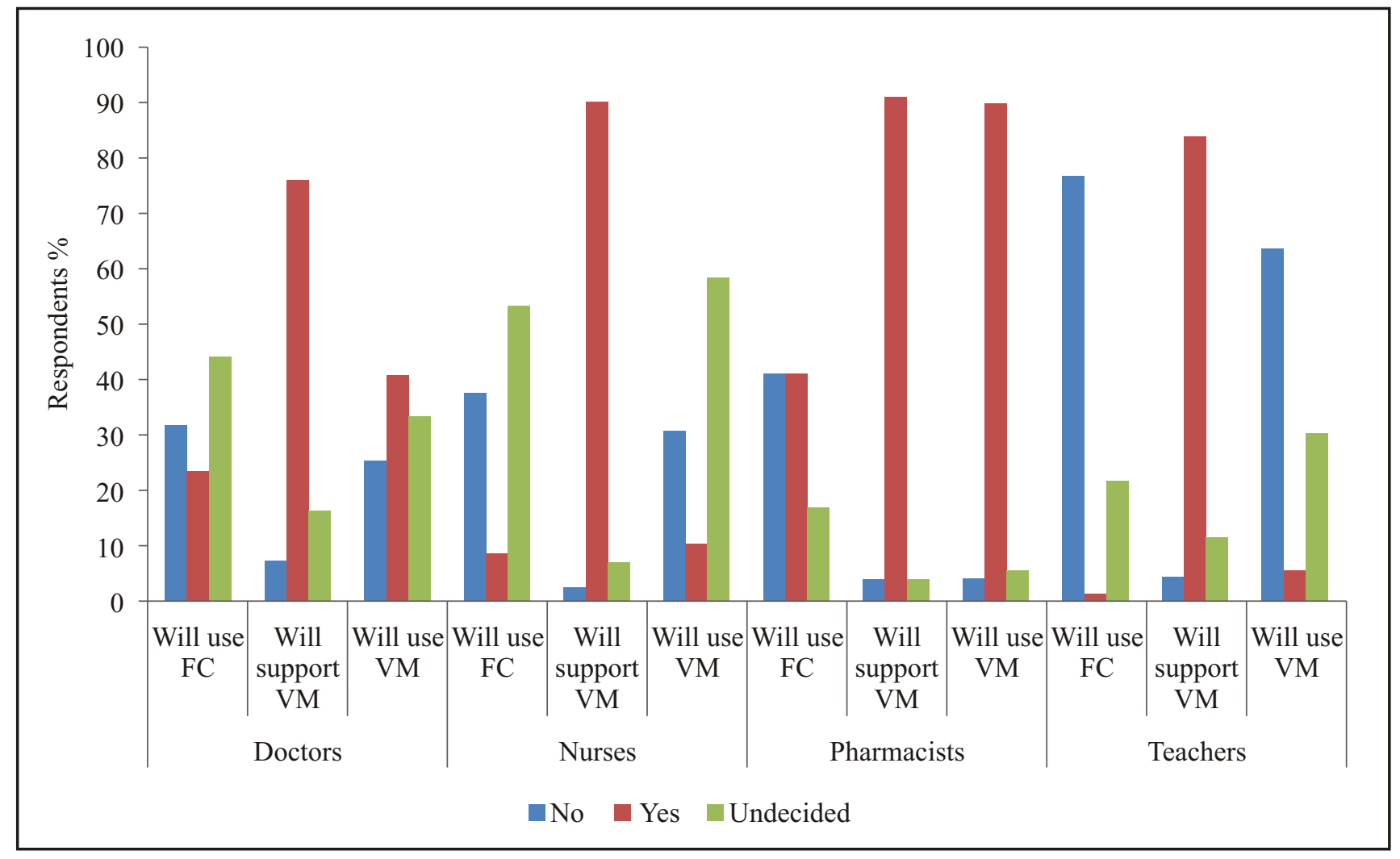

Keys: $\mathrm{FC}=$ Female condom; $\mathrm{VM}=$ Vaginal microbicide

Table 4: Association between use of male condom and willingness to use female-controlled HIV/STI prevention options after controlling for possible confounders

\begin{tabular}{|l|l|c|c|c|c|c|c|}
\hline Female contraception & \multicolumn{1}{|c|}{ Male contraception } & Odds Ratio & Std. Err. & $\mathbf{z}$ & P>z & \multicolumn{3}{|c|}{$\begin{array}{c}\text { 95\% Conf. } \\
\text { Interval] }\end{array}$} \\
\hline Will use Vaginal Microbicide & Ever used male condom & 0.4 & 0.22 & -1.63 & 0.1 & 0.1 & 1.2 \\
& Presently use male condom & 1.3 & 0.38 & 0.84 & 0.4 & 0.7 & 2.3 \\
\hline Will support Vaginal & Presently use male condom & 1.3 & 0.66 & 0.44 & 0.7 & 0.4 & 3.5 \\
Microbicide & Ever used male condom & 1.5 & 1.10 & 0.5 & 0.6 & 0.3 & 6.4 \\
\hline
\end{tabular}

\section{Discussion}

This study suggests that professionals would support female-controlled HIV/STI prevention options particularly the vaginal microbicides, a finding which is similar to earlier reports from other parts of the world. ${ }^{12,13,22-24}$ As in these earlier reports, we found a big support by these professionals for a policy which allows women to determine their HIV/STI prevention options. Taken together, these reports suggest a growing global consensus on the need to empower women to protect themselves from HIV and other STIs.

The finding that significantly fewer women would be willing to support their spouses' decisions to use either the female condoms or the vaginal microbicides suggests that ultimately the decision to use any of these products might depend largely on the women. However this observation, which challenges the widely acknowledged power imbalance with respect to sexual decisions in favor of the men, ${ }^{23}$ should be interpreted with caution. It is likely that this observation might relate specifically to our study population who were a highly socio-economically empowered group. Similar assertiveness might not be found among the less empowered lower socio-economic classes of women.

We had proposed that since the female condom is also a female-controlled HIV/STI prevention option, factors associated with its use might also affect the use of the vaginal microbicide. 
Table 5: Multivariable logistic regression analysis of the factors associated with willingness to use the female condom and vaginal microbicide

\begin{tabular}{|l|c|c|c|c|c|c|}
\hline Female contraception & Odds Ratio & Std. Err. & $\mathbf{Z}$ & \multicolumn{2}{|c|}{$\mathbf{P}>\mathbf{z}$} & \multicolumn{2}{|c|}{ [95\% Conf. Interval] } \\
\hline Female condom & & & & & & \\
\hline Gender (M vs. F) & 1.1 & 0.3 & 0.35 & 0.7 & 0.6 & 1.9 \\
\hline No of sexual partners & 1.2 & 0.4 & 0.71 & 0.5 & 0.7 & 2.2 \\
\hline Age group & 1.0 & 0.1 & -0.17 & 0.9 & 0.7 & 1.3 \\
\hline Marital Status & 0.4 & 0.2 & -2.39 & 0.017 & 0.2 & 0.9 \\
\hline Profession & 0.8 & 0.04 & -3.9 & $<0.001$ & 0.7 & 0.9 \\
\hline Duration in profession & 0.7 & 0.1 & -2.44 & 0.015 & 0.5 & 0.9 \\
\hline Perception of HIV risk & 2.2 & 0.5 & 3.11 & 0.002 & 1.3 & 3.5 \\
\hline Vaginal microbicide & & & & & & \\
\hline Age group & 0.8 & 0.1 & -1.37 & 0.2 & 0.6 & 1.1 \\
\hline No of sexual partners & 3.3 & 1.6 & 2.48 & 0.013 & 1.3 & 8.5 \\
\hline Gender & 2.8 & 0.9 & 3.24 & 0.001 & 1.5 & 5.2 \\
\hline Marital status & 0.3 & 0.1 & -2.59 & 0.01 & 0.1 & 0.8 \\
\hline Perception of HIV risk & 3.6 & 1.1 & 4.17 & $<0.001$ & 2.0 & 6.7 \\
\hline Profession & 0.9 & 0.05 & -2.79 & 0.005 & 0.8 & 0.9 \\
\hline Duration in profession & 0.6 & 0.1 & -2.31 & 0.021 & 0.4 & 0.9 \\
\hline
\end{tabular}

In this study however, we did not find any association between willingness to use the female condom and willingness to use the vaginal microbicide, although some of the independent predictors of willingness to use the female condom were also independent predictors of willingness to use the vaginal microbicide. It is likely that these independent predictors which were common to both products operate at different levels. The possible implication of this finding is that the pattern of female condom utilization might not correctly predict the pattern of vaginal microbicide utilization.

The finding that fewer number of respondents have seen the female condom compared to those who have heard of it might reflect the fact that many of those who have not seen it were either not sexually active or were in a monogamous relationship, and therefore did not need a female condom. Alternatively, this might reflect poor social marketing of the female condom. The third possible reason for fewer people having seen the female condom could relate to the finding that only few pharmacists, who should be marketing these products, have heard of the female condom, more than a decade after its introduction into the market.

In contrast to the female condom, majority would be willing to support the use of the vaginal microbicides, even though fewer numbers will be willing to use it themselves even if they knew that it was effective in preventing HIV/STI. The strong association between sexual activity and perception of personal risk of HIV infection on the one hand, and willingness to use the vaginal microbicides on the other hand is similar to the report by Bentley et al. ${ }^{25}$ suggesting that HIV risk perception might play a crucial role in an individual's decision to use vaginal microbicides. Furthermore, our data suggests that while these professionals may not use the microbicides because of their low HIV risk, they would readily recommend it to those who are at higher risk of HIV, a finding that is important for the social marketing of the microbicide.

In this study, we found no association between previous and current male condom use with willingness to use vaginal microbicide, contrary to the fears expressed by some workers that the microbicides when eventually approved will replace the condom and if not efficacious might have a negative impact on HIV control. ${ }^{26}$ This finding is similar to the observation by Malow et $a l_{.}{ }^{27}$ that condom use rate did not decrease because of the presence of alternative HIV/STI prevention methods. In addition, our findings highlights the problems with extrapolating results of acceptability and other behavioral studies involving the male condom to vaginal microbicides.

The issues identified in this study which might affect the acceptability of these products such as fear of possible side effects, potential effects on sexual enjoyment, and cultural, 
religious and social concerns, are similar to those reported by earlier workers. ${ }^{12,15,28,29}$ While clinical safety issues are being addressed, it might be important to also consider these socio-anthropological issues to ensure that any product developed achieves the desired utility.

This study was conducted among professionals practicing in the city. Therefore extrapolating the results of our findings to professionals working in other parts of the country especially in rural communities should be done with caution. Furthermore, it is not clear how our findings might relate to other professionals such as lawyers and medical laboratory scientists; however, the similarity in the responses across all the professions considered suggests that the findings with these groups might be similar.

\section{Conclusion}

There is a strong support for female-controlled HIV/STI prevention options among doctors, nurses, pharmacists and secondary school teachers in Dhaka city of Bangladesh, particularly the vaginal microbicide. Such support would inform the design of appropriate interventions to prepare these professionals for the eventual advent of an effective microbicide as a HIV/AIDS prevention option. There is need to determine the applicability of these findings to other professional groups, and other professionals working in other parts of Bangladesh, as such knowledge will inform better social marketing strategies for these products.

\section{Disclosure}

The authors report no conflicts of interest in this work.

\section{References}

1. Forbes A. Women and HIV. Microbicides for HIV prevention. Beta 2006;18:37-41.

2. World health organization. Women and microbicides. http://www.who.int/mediacentre/factsheets/fs246/en/ (accessed May 2012)

3. Howett MK, Kuhl JP. Microbicides for prevention of transmission of sexually transmitted diseases. Curr Pharm Des 2005;11:3731-46.

4. Da Costa P. AIDS in the Gambia. Afr Rep 1994;39:52-3.

5. Bauer HM, Gibson P, Hernandez M, Kent C, Klausner $\mathrm{J}$, Bolan $\mathrm{G}$. Intimate partner violence and high-risk sexual behaviors among female patients with sexually transmitted diseases. Sex Transm Dis 2002;29:411-6.

6. Maman S, Mbwambo JK, Hogan NM, Kilonzo GP, Campbell JC, Weiss E, Sweat MD. HIV-positive women report more lifetime partner violence: findings from a voluntary counseling and testing clinic in Dar es Salaam, Tanzania. Am J Public Health 2002;92:1331-7.

7. UNAIDS/WHO. AIDS Epidemic Update 2005. Geneva: Joint United Nations Programme on HIV/AIDS \& World Health Organisation, 2005.
8. American Health Consultants. Microbicides, vaccines will cut unintended pregnancies and STDs. Contracept Technol Update 2000;21:1-3.

9. Darroch JE, Frost JJ. Women's interest in vaginal microbicides. Fam Plann Perspect 1999;31:16-23.

10. Kerrigan D, Mobley S, Rutenberg N, Fisher A, Weiss E. The Female Condom: Dynamics of Use in Urban Zimbabwe. New York: Horizons, Population Council, 2000 .

11. Forbes A. Microbicides: putting women in control. World 1998;89:4-5.

12. Nweneka CV, Mayuku AU. Acceptability of femalecontrolled HIV/STI prevention options by Nigerian professionals - an exploratory study. Afr J AIDS Res 2004;3:179-82.

13. Hammett TM, Mason TH, Joanis CL, Foster SE, Harmon P, Robles RR, et al. Acceptability of formulations and application methods for vaginal microbicides among drug-involved women: results of product trials in three cities. Sex Transm Dis 2000;27:119-26.

14. [No authors listed]. Vaginal microbicides needed for female-controlled prevention. Contracept Technol Update 1999;20:25-7.

15. Coggins C, Blanchard K, Friedland B. Men's attitudes towards a potential vaginal microbicide in Zimbabwe, Mexico and the USA. Reprod Health Matters 2000;8:132-41.

16. Adeokun L, Mantell JE, Weiss E, Delano GE, Jagha T, Olatoregun $\mathrm{J}$, et al. Promoting Dual Protection in Family Planning Clinics In Ibadan, Nigeria. Int Fam Plan Perspect 2002;28:87-95.

17. Mantell JE, Hoffman S, Weiss E, Adeokun L, Delano G, Jagha T, et al. The acceptability of the female condom: perspectives of family planning providers in New York City, South Africa, and Nigeria. J Urban Health 2001;78:658-68.

18. [No authors listed]. Vaginal microbicides: how do you kick-start a global market? AIDS Anal Afr 1996;6:1.

19. [No authors listed]. Promising HIV preventive may put women in control. AIDS Wkly Plus 1999:11-12.

20. Heise L. Topical microbicides: missing link for HIV prevention. Sex Health Exch 1999;1:3-5.

21. Mantell JE, Myer L, Carballo-Dieguez A, Stein Z, Ramjee G, Morar NS, Harrison PF. Microbicide acceptability research: current approaches and future directions. Soc Sci Med 2005;60:319-30.

22. Holt BY, Morwitz VG, Ngo L, Harrison PF, Whaley KJ, Pettifor A, Nguyen AH. Microbicide preference among young women in California. $J$ Womens Health (Larchmt) 2006;15:281-94. 
23. Moon MW, Khumalo-Sakutukwa GN, Heiman JE, Mbizvo MT, Padian NS. Vaginal microbicides for HIV/STI prevention in Zimbabwe: what key informants say. J Transcult Nurs 2002;13:19-23.

24. Weeks MR, Mosack KE, Abbott M, Sylla LN, Valdes B, Prince M. Microbicide acceptability among high-risk urban U.S. women: experiences and perceptions of sexually transmitted HIV prevention. Sex Transm Dis 2004;31:682-90.

25. Bentley ME, Fullem AM, Tolley EE, Kelly CW, Jogelkar N, Srirak N, et al. Acceptability of a microbicide among women and their partners in a 4country phase I trial. Am J Public Health 2004;94:1159-64.

26. Chen FH. The impact of microbicides and changes in condom usage on HIV prevalence in men and women. AIDS 2006;20:1551-3.

27. Malow RM, Ziskind D, Jones DL. Use of femalecontrolled microbicidal products for HIV risk reduction. AIDS Care 2000;12:581-8.

28. Bentley ME, Morrow KM, Fullem A, Chesney MA, Horton SD, Rosenberg Z, et al. Acceptability of a novel vaginal microbicide during a safety trial among lowrisk women. Fam Plann Perspect 2000;32:184-8.

29. Morrow K, Rosen R, Richter L, Emans A, Forbes A, Day $\mathrm{J}$, et al. The acceptability of an investigational vaginal microbicide, PRO $2000 \mathrm{Gel}$, among women in a phase I clinical trial. $J$ Womens Health (Larchmt) 2003;12:655-66. 